\title{
HERANÇA DA RESISTÊNCIA A Stemphylium solani E INSENSIBILIDADE A SUA FITOTOXINA EM CULTIVARES DE ALGODOEIRO
}

\author{
YESHWANT R. MEHTA ${ }^{1} \&$ CARLOS A.A. ARIAS ${ }^{2}$
}

\author{
${ }^{1}$ Area de Proteção de Plantas, IAPAR, Cx. Postal 481, CEP 86001-970 Londrina, PR.; Bolsista CNPq, \\ e-mail: yrmehta@pr.gov.br; ${ }^{2}$ Eng. Agrôn., M.Sc., Embrapa-Centro nacional de Pesquisa de soja \\ (Embrapa soja),Cx. Postal 231, Londrina, PR., e-mail: arias@cnpso.embrapa.br
}

(Aceito para publicação em14/08/2001)

Autor para correspondência: Y.R. Mehta

MEHTA, Y.R., \& ARIAS, C.A.A. Herança da resistência a Stemphylium solani e insensibilidade a sua fitotoxina em cultivares de algodoeiro. Fitopatologia Brasileira 26:761-765. 2001.

\section{RESUMO}

A mancha preta do algodoeiro (Gossypium hirsutum) causada por Stemphylium solani ocorre em várias regiões produtoras de algodão do Brasil, causando severos prejuízos em rendimento especialmente no Estado do Paraná. Estudouse a herança da resistência a $S$. solani e sua fitotoxina, em três cultivares de algodoeiro. As cultivares de algodoeiro PR 94-82, PR 94-215 e CNPA Precoce 2 identificadas como resistentes foram cruzadas com a cultivar suscetível IAPAR 71, inclusive cruzamentos recíprocos. Aos 30 dias de idade, duas folhas de cada planta foram inoculadas com um isolado agressivo de $S$. solani, e outras duas da mesma planta foram infiltradas com seu filtrado contendo fitotoxina(s) na diluição de 1:1. A severidade da área foliar infetada (AFI) pelo patógeno e a área foliar necrosada pelo filtrado (AFN) foram avaliadas sete dias após a inoculação/infiltração. Considerando as reações de 740 plantas segregantes, o coeficiente de correlação entre AFI e AFN foi alto $(r=0,70)$. Os modelos de média e de variância confirmaram a predominância de efeitos genéticos aditivos para AFI e AFN. O modelo de segregação simples incluindo um único gene na determinação do caráter produzindo uma proporção de 1:2:1 foi aceito pelo teste de qui-quadrado para os cruzamentos IAPAR 71 x PR94-82 e IAPAR 71 x CNPAPRECOCE 2. Para o cruzamento IAPAR 71 x PR94-215, o padrão de segregação incluindo dois genes e epistasia $(9: 6: 1)$ foi aceito pelo teste de qui-quadrado.

Palavras-chave adicionais: Gossypium hirsutum, resistência genética.

\section{ABSTRACT \\ Inheritance of resistance to Stemphylium solani and to its phytotoxin in cotton cultivars}

Leaf blight of cotton (Gossypium hirsutum) caused by Stemphylium solani occurs in several cotton growing areas of Brazil, and causes severe yield losses especially in the State of Paraná. The inheritance of resistance to $S$. solani and to its phytotoxin was investigated in three cotton cultivars. Crosses including reciprocals were made between the cotton cultivars PR 94-82, PR 94-215 and CNPA Precoce 2, identified as resistant, and cv. IAPAR 71 as susceptible. Thirty days after sowing, two leaves of each plant were inoculated with S. solani, and the other two leaves of the same plant were infiltrated with the toxin containing culture filtrate of the same isolate at a dilution of $1: 1$. The percent of leaf area infected by the pathogen

\section{INTRODUÇÃO}

A mancha preta do algodoeiro (Gossypium hirsutum L.) causada por Stemphylium solani Weber ocorre em várias regiões produtoras de algodão do Brasil, causando severos prejuízos em rendimento especialmente no Estado do Paraná (Lima et al., 1997; Mehta, 1998; Andrade et al., 1999). O
(LAI) and the percent of necrotic leaf area caused by the culture filtrate (LAN) were evaluated seven days after inoculation. Considering the reactions of 740 segreganting plants, the coefficient of correlation between the LAI and LAN was high $(\mathrm{r}=0.70)$. The segregating populations of the three crosses showed significant additive genetic variation for LAI and LAN. A F3 based chi-square $\left(\chi^{2}\right)$ testing for the 1:2:1 ratio for a single non-dominant gene segregation was not rejected $(\mathrm{P}=0.001)$ for the crosses IAPAR $71 \times$ PR94-82 and IAPAR 71 x CNPA-PRECOCE 2. For the cross IAPAR $71 \times$ PR94-215, the pattern of segregation including two genes and epistasis $(9: 6: 1)$ was accepted by the $\chi 2$ test. patógeno ataca apenas as folhas e as infecções de maçã e do colmo até agora não foram observadas. Relativamente poucos estudos foram realizados até agora para caracterizar resistência varietal a $S$. solani em algodoeiro. Francovig et al. (1999) reportaram algumas cultivares de algodoeiro altamente resistentes e outras altamente suscetíveis a $S$. solani. Utilizando-se 14 isolados monosporicos de S. solani 
e 48 cultivares de algodoeiro, Francovig et al. (1999) classificaram os isolados de acordo com o seu grau de agressividade mas não encontraram evidências claras sobre a existência de virulência entre os isolados.

Recentemente, Mehta \& Brogin (2000) reportaram que S. solani do algodoeiro produzia fitotoxina, a qual após infiltração nas folhas do algodoeiro provocava sintomas semelhantes àqueles produzidos pelo $S$. solani. Os mesmos autores reportaram também que apenas as cultivares suscetíveis a $S$. solani eram sensíveis a fitotoxina e as cultivares resistentes eram insensíveis, sendo a fitotoxina foi considerada um fator de patogenicidade. Se a resistência a fitotoxina fosse herdada da mesma forma que a resistência a $S$. solani, então a seleção para resistência ao nível de calo ou nas gerações segregantes iniciais, poderia ser feita utilizando-se a fitotoxina e conseqüentemente, o processo de melhoramento genético poderia ser acelerado. O objetivo do presente trabalho foi estudar a herança genética da resistência a $S$. solani e sua fitotoxina, em três cultivares de algodoeiro brasileiro.

\section{MATERIAIS E MÉTODOS}

As cultivares de algodoeiro PR 94-82 (IAC 87-544), PR 94-215 (CS 189) e CNPA Precoce 2 (C25-6-79/PNH3), anteriormente identificadas como resistentes a $S$. solani, foram cruzadas com a cultivar suscetível IAPAR 71 (Paraná 3, Seleção de IAS 20) (Francovig et al., 1999; Mehta \& Brogin, 2000). Cruzamentos recíprocos também foram realizados. Antes de realizar os cruzamentos, plantas provenientes de uma semente de cada progenitor foram autofecundadas para obter sementes puras. Dez sementes de cada F1 foram semeadas para obter sementes da geração F2. Quinze sementes de cada F2 foram semeadas para obter sementes de 15 famílias F3. Sementes das gerações F1, F2, e dos progenitores, foram multiplicadas paralelamente em todas as fases do trabalho para evitar o efeito da idade de sementes na expressão dos sintomas da doença. Para o experimento de herança, 20 sementes de cada progenitor foram semeadas juntamente com 50 sementes de cada F2 e 60 sementes de F3 (quatro sementes de cada uma das 15 famílias de F3), totalizando uma população de 740 plantas.

Para inoculação a suspensão de conídios foi ajustada a $3.0 \times 10^{3}$ conídios $/ \mathrm{ml}$ e algumas gotas de Tween 20 foram adicionadas a esta suspensão. Para este fim, o isolado de $S$. solani foi cultivado em placas de Petri contendo $10 \mathrm{ml} \mathrm{de}$ meio de cultura V8-agar por dez dias a $21^{\circ} \mathrm{C}$. As colônias foram raspadas com pincel para retirada dos conídios. $\mathrm{O}$ filtrado de fitotoxina foi preparado conforme descrito anteriormente (Mehta \& Brogin, 2000). Aos 30 dias de idade, duas folhas de cada planta foram inoculadas com um isolado agressivo de $S$. solani (No. 11687 da coleção do IAPAR), e outras duas da mesma planta foram infiltradas com seu filtrado contendo fitotoxina(s) na diluição de 1:1, e foram incubadas em câmara de crescimento ajustado à $21^{\circ} \mathrm{C}$ e à UR do ar de $95 \%$ por $24 \mathrm{~h}$. A inoculação e infiltração foram realizadas utilizando-se um pincel embebido na suspenção de inóculo ou fitotoxina e foi passado individualmente em cada folha sem causar ferimento (Mehta \& Brogin, 2000). Após este período as plantas foram transferidas e casualizadas em casa de vegetação.

A severidade da área foliar infetada (AFI) pelo patógeno e a área foliar necrosada pelo filtrado (AFN) foram avaliadas sete dias após a inoculação/infiltração utilizando uma escala visual de 0-99\% (Mehta, 1998; Mehta \& Brogin, 2000). A porcentagem de AFI/AFN de $0-1 \%$ foi considerada resistente, de $2-5 \%$ moderadamente suscetível, e $>5 \%$ como suscetível. Os dados foram analisados através de médias e variâncias das diferentes gerações utilizando os "softwares" GENFIT e SGQ (Mather \& Jinks, 1982). Utilizou-se também o método do qui-quadrado para verificar a adequação dos modelos de segregação genética sugeridos. O coeficiente de correlação entre a AFI/AFN foi verificado através da análise de regressão utilizando-se o programa "Cricket Graph" versão 1.01 , do sistema Macintosh. Foi feita a análise quantitativa (Mather \& Jinks, 1982) sobre os progenitores (P1, P2) e as duas gerações (F2, F3) para a estimação de quatro componentes do modelo genético. Os modelos genéticos aplicados sobre médias relacionadas às linhas puras e gerações derivadas de cruzamentos entre elas são (Mather \& Jinks, 1982):

$$
\begin{aligned}
& \overline{\mathrm{P}}_{1}=\mathrm{m}+[\mathrm{d}]+[\mathrm{i}] \\
& \overline{\mathrm{P}}_{2}=\mathrm{m}-[\mathrm{d}]+[\mathrm{i}] \\
& \overline{\mathrm{F}}_{2}=\mathrm{m}+\frac{1}{2}[\mathrm{~h}]+\frac{1}{4}[\mathrm{l}] \\
& \overline{\mathrm{F}}_{3}=\mathrm{m}+\frac{1}{4}[\mathrm{~h}]+\frac{1}{16}[\mathrm{l}] \\
& \overline{\mathrm{P}}_{1}=\mathrm{m}+[\mathrm{d}]+[\mathrm{i}] \\
& \overline{\mathrm{P}}_{2}=\mathrm{m}-[\mathrm{d}]+[\mathrm{i}] \\
& \overline{\mathrm{F}}_{2}=\mathrm{m}+\frac{1}{2}[\mathrm{~h}]+\frac{1}{4}[\mathrm{l}] \\
& \overline{\mathrm{F}}_{3}=\mathrm{m}+\frac{1}{4}[\mathrm{~h}]+\frac{1}{16}[\mathrm{l}]
\end{aligned}
$$

onde:

m é o efeito genético e ambiental comum no cruzamento entre linhas puras;

[d] é o efeito genético aditivo;

[h] é o efeito genético de dominância;

[i] é o efeito genético da interação aditiva $\mathrm{x}$ aditiva;

[1] é o efeito genético da interação dominante $\mathrm{x}$ dominante.

Os modelos genéticos aplicados sobre as variâncias das gerações estudadas foram:

$\mathrm{V}_{\mathrm{P} 1}=\mathrm{E} ;$
$\mathrm{V}_{\mathrm{P} 2}=\mathrm{E} ;$ 
Herança da resistência a Stemphylium solani e insensibilidade...

$\mathrm{V}_{\mathrm{F} 2}=1 / 2 \mathrm{D}+1 / 4 \mathrm{H}+\mathrm{E}$;

$\mathrm{V}_{1 \mathrm{~F} 3}($ entre familias $)=1 / 2 \mathrm{D}+1 / 16 \mathrm{H}+(1 / \mathrm{n}) \mathrm{V}_{2 \mathrm{~F} 3}$, e

$\mathrm{V}_{2 \mathrm{~F} 3}($ dentro de familias $)=1 / 4 \mathrm{D}+1 / 8 \mathrm{H}+\mathrm{E}$.

onde:

$\mathrm{V}_{\mathrm{P} 1}, \mathrm{~V}_{\mathrm{P} 2}, \mathrm{~V}_{\mathrm{F} 2}, \mathrm{~V}_{1 \mathrm{~F} 3}$ e $\mathrm{V}_{2 \mathrm{~F} 3}$ são, respectivamente, as variâncias do parental 1, parental 2, geração $F_{2}$, entre e dentro de famílias $\mathrm{F}_{3}$;

$\mathrm{D}$ é a variância genética aditiva;

H é a variância genética de dominância;

E é a variância ambiental aditiva, e

$\mathrm{n}$ é o número de indivíduos dentro das famílias F3.

\section{RESULTADOS \& DISCUSSÃO}

Para os estudos da resistência, a realização de cruzamentos recíprocos e avaliações de gerações F2, F3, são mais preferidos do que os cruzamentos dialélicos (Mather \& Jinks, 1982). Segundo Francovig et al. (1999), a severidade da doença foi maior na fase de plântula do que na fase de planta adulta. No presente trabalho, as inoculações com o patógeno e as infiltrações com a fitotoxina foram realizadas apenas na fase de plântulas.

Todas as plantas dos progenitores resistentes (PR 9482, PR94-215 e CNPA PRECOCE 2) demonstraram resistência a $S$. solani e insensibilidade a seu filtrado contendo fitotoxina(s) (Tabela 1, Figura 1). Similarmente, as plantas da cv. suscetível IAPAR 71, demonstraram suscetibilidade e sensibilidade a $S$. solani e seu filtrado, respectivamente.

Para os cruzamentos IAPAR 71 x PR94-82 e IAPAR 71 x CNPA-PRECOCE 2, a magnitude do efeito genético aditivo [d] foi relativamente alta e se aproximou do valor médio (m) de cada cruzamento (Tabelas 2 e 3). A dominância [h] também apresentou valores relativamente elevados. Para o cruzamento IAPAR 71 x PR94-215, o modelo se ajustou com [d] e com [i], tanto para AFI como para AFN. A presença significativa de epistasia do tipo aditivo por aditivo indica a existência de mais de um gene controlando o caráter nesse cruzamento. Os modelos de variância confirmaram a presença de efeitos genéticos aditivos (D) para AFI (Tabela 1) ou de efeitos aditivos entre genes ligados (D1 e/ou D2) para AFN (Tabela 2). A presença de D1 ou D2 nos modelos indicam que mais de um gene pode estar envolvido na determinação do caráter AFN. Também foi observada, para os dois caracteres, a presença de interação genótipo x microambiente, representada pela presença de E1 e E2. O teste F aplicado para a razão entre a maior pela menor variância foi altamente significativo para todos os cruzamentos e caracteres.

Como as famílias F2:3 apresentaram padrões de reação semelhantes para os dois caracteres, o teste de qui-quadrado serve tanto para AFI como também para AFN (Tabela 4). O modelo de segregação simples incluindo um único gene na determinação do caráter e, conseqüentemente, produzindo uma proporção de 1:2:1, foi aceito pelo teste de qui-quadrado para os cruzamentos IAPAR 71 x PR94-82 e IAPAR 71 x CNPA-PRECOCE 2, com probabilidades de $15 \%$ e $48 \%$, respectivamente (Tabela 4). A resistência presente nas cultivares PR94-82 e CNPA-PRECOCE 2 é determinada individualmente por um gene dominante. Cruzamento entre estas cultivares é necessário para determinar se os genes estão no mesmo locus.

Para o cruzamento IAPAR 71 x PR94-215, as proporções observadas foram de 14:13:3 e para o mesmo modelo genético com um gene maior, produziu um valor de qui-quadrado de 8.60 e probabilidade de $1.3 \%$, sendo portanto significativo e rejeitado. Um padrão de segregação incluindo dois genes e epistasia $(9: 6: 1)$ foi aceito $(\mathrm{P}=0,49)$, confirmando

TABELA 1 - Grau de liberdade, média e variância para a porcentagem de área foliar infetada por Stemphylium solani (AFI) e necrosada por sua fitotoxina (AFN) em diferentes genótipos de algodoeiro (Gossypium hirsutum) e respectivas gerações $F 2$ e F3 de seus cruzamentos

\begin{tabular}{|c|c|c|c|c|c|c|}
\hline \multirow{2}{*}{ População } & \multicolumn{3}{|c|}{ AFI (\%) } & \multicolumn{3}{|c|}{ AFN (\%) } \\
\hline & gl & média & var & gl & média & var \\
\hline \multicolumn{7}{|c|}{ Genótipo } \\
\hline IAPAR 71 & 17 & 43,89 & 783,99 & 17 & 27,78 & 297,71 \\
\hline PR 94-82 & 19 & 0,15 & 0,13 & 19 & 0,00 & 0,00 \\
\hline PR 94-215 & 19 & 0,00 & 0,00 & 19 & 0,00 & 0,00 \\
\hline PRECOCE 2 & 15 & 0,06 & 0,06 & 15 & 0,00 & 0,00 \\
\hline \multicolumn{7}{|c|}{ Cruzamento } \\
\hline \multicolumn{7}{|c|}{ IAPAR 71 x PR 94-82 } \\
\hline F2 & 96 & 5,21 & 146,50 & 96 & 3,71 & 69,56 \\
\hline F3 Total & 115 & 9,14 & 294,86 & 115 & 6,67 & 153,05 \\
\hline Entre & 29 & & 605,54 & 29 & & 225,59 \\
\hline Dentro & 86 & & 185,01 & 86 & & 127,40 \\
\hline \multicolumn{7}{|c|}{ IAPAR 71 x PR 94-215 } \\
\hline F2 & 95 & 4,87 & 130,23 & 95 & 3,64 & 82,86 \\
\hline F3 Total & 118 & 6,38 & 169,90 & 118 & 5,00 & 119,39 \\
\hline Entre & 29 & & 435,65 & 29 & & 263,70 \\
\hline Dentro & 89 & & 79,95 & 89 & & 70,54 \\
\hline \multicolumn{7}{|c|}{ IAPAR 71 x PRECOCE 2} \\
\hline F2 & 96 & 4,62 & 125,18 & 96 & 3,23 & 77,86 \\
\hline F3 Total & 114 & 8,84 & 176,26 & 114 & 8,56 & 218,81 \\
\hline Entre & 29 & & 400,46 & 29 & & 483,85 \\
\hline Dentro & 85 & & 95,88 & 85 & & 123,79 \\
\hline
\end{tabular}

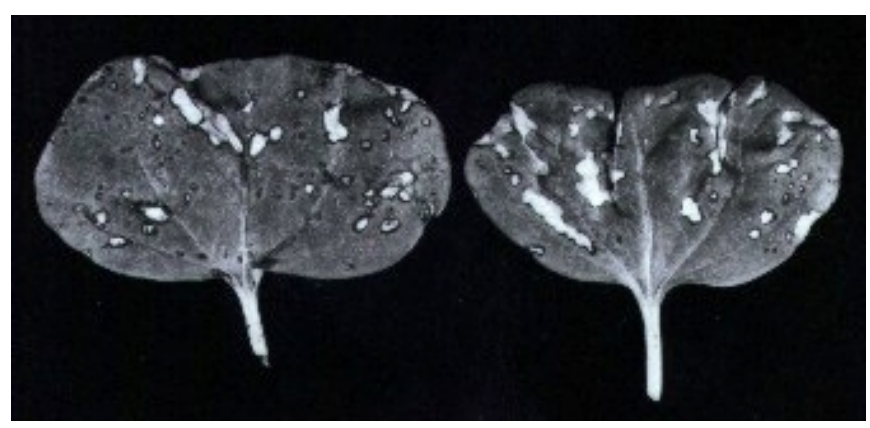

FIG. 1 - Sintomas provocados por Stemphylium solani (a esquerda) e por seu filtrado cru (sem diluição) contendo fitotoxina(s) (a direta), sete dias após a inoculação/infiltração nas folhas cotiledonares da cultivar suscetível do algodoeiro (Gossypium hirsutum) IAPAR 71. 
TABELA 2 - Parâmetros genéticos ajustados às médias e as variâncias e herdabilidade no sentido restrito ao nível de famílias $F 3$ para a área foliar infetada por Stemphylium solani nas populações de três cruzamentos de cultivares de algodoeiro (Gossypium hirsutum)

\begin{tabular}{|c|c|c|c|c|c|c|c|c|c|}
\hline \multirow{3}{*}{$\begin{array}{l}\text { Parâmetro } \\
\text { genético } \\
\mathrm{m} \\
{[\mathrm{d}]}\end{array}$} & \multicolumn{3}{|c|}{$\begin{array}{c}\text { IAPAR 71 } \\
x \\
\text { PR94-82 }\end{array}$} & \multicolumn{3}{|c|}{$\begin{array}{c}\text { IAPAR 71 } \\
x \\
\text { PR94-215 }\end{array}$} & \multicolumn{3}{|c|}{$\begin{array}{c}\text { IAPAR 71 } \\
\text { x } \\
\text { CNPA-PRECOCE 2 }\end{array}$} \\
\hline & 17,70 & \pm & 2,37 & 5,61 & \pm & 0,83 & 16,67 & \pm & 2,10 \\
\hline & 17,55 & \pm & 2,37 & 21,94 & \pm & 3,30 & 16,61 & \pm & 2,10 \\
\hline [h] & $-26,18$ & \pm & 5,83 & - & - & - & $-25,36$ & \pm & 5,35 \\
\hline [i] & - & - & - & 16,34 & \pm & 3,40 & - & - & - \\
\hline$\chi^{2} / \mathrm{gl} / \mathrm{P}^{1 /}$ & \multicolumn{3}{|c|}{$3,55 / 1 / 0,06$} & \multicolumn{3}{|c|}{$0,82 / 1 / 0,37$} & \multicolumn{3}{|c|}{$4,34 / 1 / 0,04^{2 /}$} \\
\hline $\mathrm{D}$ & 281,15 & \pm & 35,18 & 276,42 & \pm & 26,79 & 294,95 & \pm & 28,82 \\
\hline E1 & 573,49 & \pm & 110,33 & 820,03 & \pm & 273,34 & 820,03 & \pm & 273,34 \\
\hline E2 & 0,13 & \pm & 0,04 & 0,01 & \pm & 0,03 & 0,16 & \pm & 0,05 \\
\hline$\chi^{2} / \mathrm{gl} / \mathrm{P}$ & \multicolumn{3}{|c|}{$2,52 / 2 / 0,28$} & \multicolumn{3}{|c|}{$2,49 / 2 / 0,29$} & \multicolumn{3}{|c|}{$6,87 / 2 / 0,03^{2 /}$} \\
\hline $\mathrm{h}^{2}$ & \multicolumn{3}{|c|}{0,66} & \multicolumn{3}{|c|}{0,57} & \multicolumn{3}{|c|}{0,59} \\
\hline \multicolumn{10}{|c|}{$\begin{array}{l}\text { 1/ Qui-quadrado }\left(\chi^{2}\right) \text {, graus de liberdade }(\mathrm{gl}) \text { e probabilidade }(\mathrm{P}) \text { para o modelo } \\
\text { proposto. } \\
\text { 2/ Melhor modelo encontrado. } \\
\mathrm{h}^{2}=\text { herdabilidade }\end{array}$} \\
\hline
\end{tabular}

TABELA 3 - Parâmetros genéticos ajustados às médias e variâncias e herdabilidade no sentido restrito ao nível de famílias F3, para a área foliar necrosada por filtrado de Stemphylium solani nas populações de três cruzamentos de algodoeiro (Gossypium hirsutum)

\begin{tabular}{|c|c|c|c|c|c|c|c|c|c|}
\hline \multirow{2}{*}{$\begin{array}{c}\begin{array}{l}\text { Parâmetro } \\
\text { genético }\end{array} \\
\mathrm{m}\end{array}$} & \multicolumn{3}{|c|}{$\begin{array}{c}\text { IAPAR 71 } \\
\text { x } \\
\text { PR94-82 } \\
\end{array}$} & \multicolumn{3}{|c|}{$\begin{array}{c}\text { IAPAR } 71 \\
\text { x } \\
\text { PR94-215 } \\
\end{array}$} & \multicolumn{3}{|c|}{$\begin{array}{c}\text { IAPAR } 71 \\
x \\
\text { CNPA-PRECOCE } 2\end{array}$} \\
\hline & 12,15 & \pm & 1,56 & 4,27 & \pm & 0,68 & 13,89 & \pm & 1,66 \\
\hline [d] & 12,15 & \pm & 1,56 & 13,89 & \pm & 2,03 & 13,89 & \pm & 1,67 \\
\hline$[\mathrm{h}]$ & $-17,49$ & \pm & 3,85 & - & - & - & $-21,32$ & \pm & 4,03 \\
\hline [i] & - & - & - & 9,62 & \pm & 2.14 & - & - & - \\
\hline$\chi^{2 / g 1 / \mathrm{P}^{1 /}}$ & \multicolumn{3}{|c|}{$, 79 / 1 / 0,18$} & \multicolumn{3}{|c|}{$0,99 / 1 / 0,32$} & \multicolumn{3}{|c|}{$0,001 / 1 / 0,97$} \\
\hline $\mathrm{D}$ & - & - & - & - & - & - & - & - & - \\
\hline D1 & 327,42 & \pm & 88,55 & 71,33 & \pm & 24,66 & 159,95 & \pm & 21,58 \\
\hline D2 & - & - & - & - & - & - & 501,23 & \pm & 75,99 \\
\hline E1 & 280,92 & \pm & 37,41 & 225,81 & \pm & 44,73 & 297,71 & \pm & 102,11 \\
\hline E2 & 0,10 & \pm & 0,03 & 0,10 & \pm & 0,03 & 0,10 & \pm & 0,04 \\
\hline$\chi^{2 / g l / P}$ & \multicolumn{3}{|c|}{$4,55 / 2 / 0,10$} & \multicolumn{3}{|c|}{$2,96 / 2 / 0,23$} & \multicolumn{3}{|c|}{$0,28 / 1 / 0,60$} \\
\hline $\mathrm{h}^{2}$ & \multicolumn{3}{|c|}{0,82} & \multicolumn{3}{|c|}{0,56} & \multicolumn{3}{|c|}{0,82} \\
\hline
\end{tabular}

um controle genético mais complexo na determinação da resistência neste cruzamento. Portanto, na cultivar PR94-215, a resistência foi determinada pela presença de dois genes dominantes com efeito epistático complementar.

A magnitude das variâncias dos materiais resistentes é mínima, já que todas as medidas da área foliar foram de baixa magnitude (Tabela 1). As variâncias para AFI e AFN para a cultivar suscetível foram elevadas e indicam uma grande variação da reação entre indivíduos dentro da cultivar. Como essas cultivares parentais são derivadas de uma única planta obtidas através de autofecundação, essas variâncias servem como estimadores da variância ambiental aditiva. Em função dessa diferença de magnitude entre variâncias, denominada heterogeneidade de variâncias, foi necessário subdividir o
TABELA 4 - Teste de qui-quadrado para as padrões de segregação para área foliar infetada e para a área foliar necrosada, baseado nas reações das populações segregantes

\begin{tabular}{|c|c|c|c|c|c|c|}
\hline \multirow{3}{*}{$\begin{array}{l}\text { Categoria } \\
\text { de reação }{ }^{1 /}\end{array}$} & \multicolumn{6}{|c|}{$\begin{array}{l}\text { Frequência de plantas observadas (Obs) e } \\
\text { esperadas (Esp) por cruzamento }\end{array}$} \\
\hline & \multicolumn{2}{|c|}{$\begin{array}{c}\text { IAPAR } 71 \\
\text { x } \\
\text { PR94-82 }\end{array}$} & \multicolumn{2}{|c|}{$\begin{array}{c}\text { IAPAR } 71 \\
x \\
\text { PR94-215 }\end{array}$} & \multicolumn{2}{|c|}{$\begin{array}{c}\text { IAPAR } 71 \\
x \\
\text { CNPA Precoce 2 }\end{array}$} \\
\hline & Obs & $\mathrm{Esp}^{2 /}$ & Obs & Esp $^{3 /}$ & Obs & Esp $^{2 /}$ \\
\hline RR & 12 & 7.5 & 14 & 16,87 & 10 & 7,5 \\
\hline RS & 13 & 15 & 13 & 11,25 & 12 & 15 \\
\hline SS & 5 & 7,5 & 3 & 1,88 & 8 & 7,5 \\
\hline Total & 30 & 30 & 30 & 30 & 30 & 30 \\
\hline$\chi^{2} / \mathrm{df} / \mathrm{P}^{4 /}$ & \multicolumn{2}{|c|}{$3,80 / 2 / 0,15$} & \multicolumn{2}{|c|}{$1,44 / 2 / 0,49$} & \multicolumn{2}{|c|}{$1,47 / 2 / 0,48$} \\
\hline
\end{tabular}

$1 / \mathrm{RR}=$ somente indivíduos resistentes; $\mathrm{RS}=$ segregação entre resistentes e suscetíveis nas famílias F2:3

2/ Frequência esperada: $1: 2: 1$.

3/ Frequência esperada: 9:6:1.

4/ Qui-quadrado $\left(\chi^{2}\right)$, graus de liberdade (gl) e probabilidade $(\mathrm{P})$ para o modelo proposto.

efeito ambiental (E) em efeitos ambientais específicos para cada parental suscetível (E1) e resistente (E2).

Pôde-se observar que, para os dois caracteres, as médias das gerações F2 e F3 dos três cruzamentos estudados ficaram mais próximas das médias dos respectivos parentais resistentes, evidenciando a presença de efeitos genéticos não aditivos como dominância e epistasia na determinação do caráter. A presença de dominância $[\mathrm{h}]$ significativa prevaleceu no sentido da resistência e da epistasia [i] significativa no sentido da suscetibilidade (Tabela 2, 3).

Considerando as avaliações realizadas em 740 plantas incluindo as gerações F2, F3, e os progenitores, o coeficiente de correlação entre AFI e AFN foi alto $(r=0,70)$ (Figura 2). Correlação semelhante entre AFI e AFN foi obtida por Mehta \& Brogin (2000), utilizando 38 cultivares de algodoeiro com grau variável de resistência $(\mathrm{r}=0,87)$. Os resultados indicam

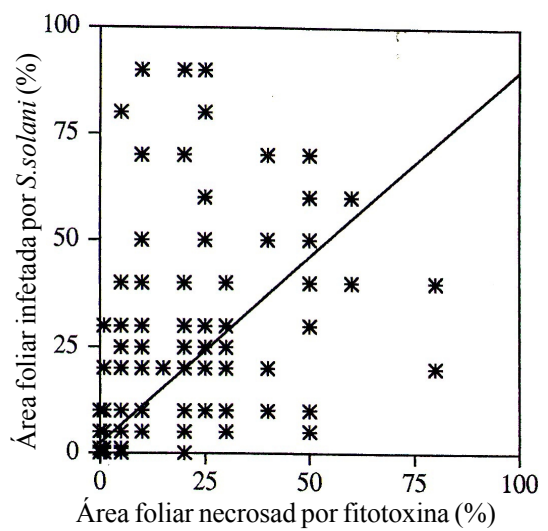

FIG. 2 - Relação entre a área foliar infetada (AFI) e a área foliar necrosada (AFN) pelo Stemphylium solani e pelo seu filtrado na diluição de 1:1, respectivamente, das folhas de $\mathbf{7 4 0}$ plantas das populações F2, F3 e dos progenitores, sete dias após a inoculação/infiltração. $(y=0,877 x+2,321$; $\mathbf{r}=\mathbf{0 , 7 0 ) \text { . }}$ 
a possibilidade de realizar seleção para resistência utilizando a fitotoxina(s) tanto ao nível de calo como também em populações segregantes no campo. Não obstante, para este fim, trabalhos futuros sobre a padronização dos sistemas de infiltração e avaliação dos calos no laboratório, e das plantas no campo, são necessários. Da mesma forma, a caracterização química da fitotoxina(s) é desejável. Este é o primeiro relato sobre a herança genética da resistência a $S$. solani em cultivares de algodoeiro.

\section{AGRADECIMENTOS}

Nosso sinceros agradecimentos ao Eléusio C. Freire, CNPA algodão, Embrapa, Paraiba, para providenciar sementes genética da cultivar CNPA-Precoce 2. O apoio técnico foi proporcionado por A. Géa, R.L. Brogin, T.K.K. Tame, E. Marcolino, A. Souza e J.A. Oliveira.

\section{REFERÊNCIAS BIBLIOGRÁFICAS}

ANDRADE, P.C., NETO, D.C. \& MACHADO, A.R.
Controle químico de doenças em algodão no Mato Grosso. Fitopatologia Brasileira 25:262. 1999. (Resumo)

FRANCOVIG, P.C., MEHTA, Y.R., FONSECA, N.S. \& REIS, E.M. Fontes de resistência em cultivares de algodoeiro a Stemphylium solani. Summa Phytopathologica 25:217-222, 1999.

LIMA, E.F., FREIRE, E.C., BATISTA, F.A.S., FARIAS, F.J.C. \& PIRES, V.A. Fungos patogênicos associados à podridão dos frutos e às manchas foliares do algodoeiro no Estado do Mato Grosso. In: Anais. $1^{\circ}$ Congresso Brasileiro de Algodão, Fortaleza. 1997. pp. 237.

MATHER, K. \& JINKS, J.L. Biometrical genetics. Chapman and Hall, London, $3^{\circ}$ Ed., 1982.

MEHTA, Y.R. Severe outbreak of Stemphylium leaf blight - a new disease of cotton in Brazil. Plant Disease 82:14. 1998.

MEHTA, Y.R. \& BROGIN, R.L. Phytotoxicity of a culture filtrate produced by Stemphylium solani of cotton. Plant Disease 84:838-842. 2000. 